\title{
International Olympic Committee consensus statement: harassment and abuse (non-accidental violence) in sport
}

\author{
Margo Mountjoy, ${ }^{1,2}$ Celia Brackenridge, ${ }^{3}$ Malia Arrington, ${ }_{1}^{4}$ Cheri Blauwet, ${ }^{5}$ \\ Andrea Carska-Sheppard, ${ }^{6}$ Kari Fasting, ${ }^{7}$ Sandra Kirby, ${ }_{1}^{8}$ Trisha Leahy, ${ }_{1}^{9}$ Saul Marks, ${ }^{2,10}$ \\ Kathy Martin, ${ }^{11,12}$ Katherine Starr, ${ }^{13}$ Anne Tiivas, ${ }^{14}$ Richard Budgett ${ }^{15}$
}

For numbered affiliations see end of article.

\section{Correspondence to Dr Margo Mountjoy, Department of Family Medicine, Michael G. DeGroote School of Medicine, McMaster University Waterloo Regional Campus. 10-B Victoria Street South, Kitchener, Hamilton N2G 1C5, Ontario, Canada; mmsportdoc@mcmaster.ca}

Accepted 30 March 2016 Published Online First 26 April 2016

\section{CrossMark}

To cite: Mountjoy $M$, Brackenridge $\mathrm{C}$,

Arrington $\mathrm{M}$, et al. $\mathrm{Br}$

Sports Med 2016;50:1019-

1029.

\section{ABSTRACT}

Despite the well-recognised benefits of sport, there are also negative influences on athlete health, well-being and integrity caused by non-accidental violence through harassment and abuse. All athletes have a right to engage in 'safe sport', defined as an athletic environment that is respectful, equitable and free from all forms of nonaccidental violence to athletes. Yet, these issues represent a blind spot for many sport organisations through fear of reputational damage, ignorance, silence or collusion. This consensus statement extends the 2007 IOC Consensus Statement on Sexual Harassment and Abuse in Sport, presenting additional evidence of several other types of harassment and abuse-psychological, physical and neglect. All ages and types of athletes are susceptible to these problems but science confirms that elite, disabled, child and lesbian/gay/bisexual/trans-sexual (LGBT) athletes are at highest risk, that psychological abuse is at the core of all other forms and that athletes can also be perpetrators. Harassment and abuse arise from prejudices expressed through power differences. Perpetrators use a range of interpersonal mechanisms including contact, noncontact/verbal, cyber-based, negligence, bullying and hazing. Attention is paid to the particular risks facing child athletes, athletes with a disability and LGBT athletes. Impacts on the individual athlete and the organisation are discussed. Sport stakeholders are encouraged to consider the wider social parameters of these issues, including cultures of secrecy and deference that too often facilitate abuse, rather than focusing simply on psychopathological causes. The promotion of safe sport is an urgent task and part of the broader international imperative for good governance in sport. A systematic multiagency approach to prevention is most effective, involving athletes, entourage members, sport managers, medical and therapeutic practitioners, educators and criminal justice agencies. Structural and cultural remedies, as well as practical recommendations, are suggested for sport organisations, athletes, sports medicine and allied disciplines, sport scientists and researchers. The successful prevention and eradication of abuse and harassment against athletes rests on the effectiveness of leadership by the major international and national sport organisations.

\section{INTRODUCTION}

Sport has long been recognised as a major contributor to positive health and well-being for participants. Nonetheless, the risk of sports-related accidental injury is widely acknowledged, especially for elite athletes, resulting in the evolution of a sophisticated research and practice community to mitigate this risk. $^{1}{ }^{2}$ Less well-recognised is the potential negative influence on athlete health and well-being if his/her integrity is challenged by non-accidental violence or maltreatment through harassment and abuse. ${ }^{3} 4$ All forms of harassment and abuse breach human rights and may constitute a criminal offence. ${ }^{3-7}$ Therefore, there is a legal and moral duty of care incumbent on those who organise sport, to ensure that risks of nonaccidental violence are identified and mitigated.

Harms caused by harassment and abuse still represent a blind spot for many sport organisations, either through fear of reputational damage or through ignorance, silence and collusion. ${ }^{8}{ }^{9}$ Research on abuse and harassment outside of sport suggests that sport agencies cannot be complacent about this: there is no good reason to suppose that sport is exempt from the ills of wider society. ${ }^{10}$ More difficult to assess is whether sport is either more or less prone to such problems, for example, whether sport is especially risky or, conversely, offers any special protection. ${ }^{11}$ What is clear is that the risk of experiencing psychological, physical and sexual violence rises as the athlete progresses up the talent ladder and performance pathway, ${ }^{12}$ and that exposure to an abusive elite sport culture can lead to a range of mental health difficulties ${ }^{14}$ and other negative impacts (see figure 1).

The cultural context of harassment and abuse is rooted in discrimination based on power differentials across a range of social and personal factors (figure 1). It remains to be seen whether and how far the addition of a non-discrimination clause to the Olympic Charter under Principle 6 in $2015^{15}$ ameliorates these problems.

Owing to the expansion of available science in the field since 2006 , the IOC convened a consensus meeting of international scientific, clinical and policy experts to review the current body of knowledge, and to provide recommendations for the prevention and management of non-accidental violence in sport. This version has been expanded beyond sexual harassment and abuse in recognition of the wider array of non-accidental violence through which athletes are maltreated, and of the additional threats and rights violations that these constitute (see box 1). ${ }^{4} 1516$ In concert with the IOC's recent Youth Athlete Development work ${ }^{17}$ and with UN terminology, ${ }^{3}$ this paper adopts the term 'violence' to describe the various nonaccidental harms perpetrated on athletes. This Consensus Statement is an update and extension of 


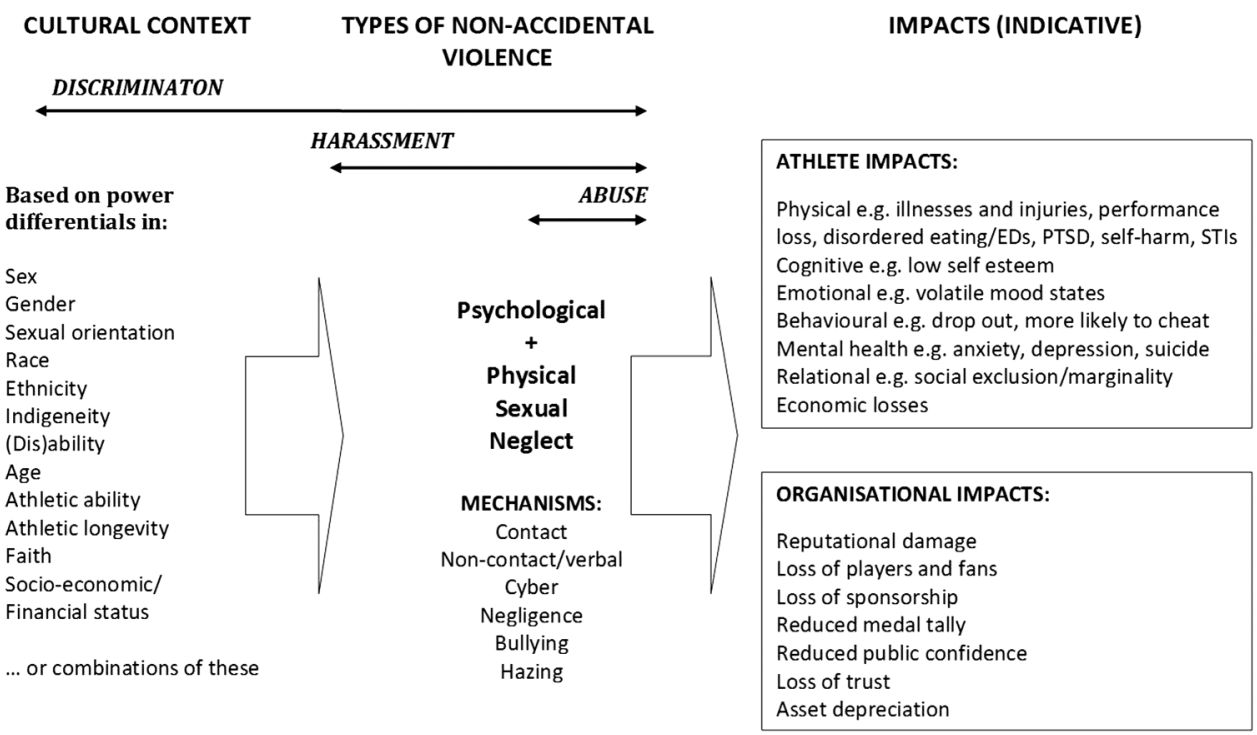

the 2007 IOC Consensus Statement on Sexual Harassment and Abuse in Sport. ${ }^{18}$

We acknowledge that the science underpinning this document is comparatively young and not yet entirely developed. For example, the predominance of available research is representative of only a few countries, and the experiences of some groups, such as athletes with disabilities and lesbian/gay/bisexual/trans-sexual (LGBT) athletes, is largely unknown. The document therefore focuses only on those areas of harassment and abuse in sport where there is deemed to be a sufficient scientific evidence base, and a prevention obligation that is not already addressed elsewhere (see figure 1). For this reason, the primary types of non-accidental violence in the document are categorised under: psychological harassment and abuse, which we regard as a conduit to other forms, sexual harassment and abuse, physical harassment and abuse, and neglect. Several mechanisms through which harassment and abuse are perpetrated are also discussed. Separate attention is paid to the increased risks of harassment and abuse in the child athlete, the athlete with a disability and the athlete who is LGBT. While each form of harassment or abuse is described here singly, it is important to note that they may also be experienced by athletes in combination, exacerbating negative effects.

This Consensus Statement should be studied in concert with several other key documents that complement and augment it, some of which address the particular needs and sensitivities of the elite child athlete. ${ }^{30} 31$ However, it is important to stress that athletes of all ages have a right to engage in 'safe sport': an athletic environment that is respectful, equitable and free from all forms of non-accidental violence to athletes. Everyone involved in sport will benefit from a sporting environment that is free from fear or favour, and are just as entitled to express their human rights in the context of sport as they are in any other setting. ${ }^{32-34}$

\section{FORMS OF ABUSE AND HARASSMENT IN SPORT}

Psychological harassment and abuse-the gateway to non-accidental violence

Psychological or emotional harassment and abuse has been the most recent form of interpersonal violence to receive research or policy attention. ${ }^{35}$ Sport research into this form of interpersonal violence is even recent with relatively scarce data and formulations based on the parent-child literature. ${ }^{25}$ There is strong evidence that sexual, physical and psychological abuse are highly correlated. ${ }^{36} 37$ Psychological abuse is at the core of all others since it is impossible to conceive of any form of harassment or abuse that does not also have psychological underpinnings.

Research on the psychological harassment and abuse in sport is primarily qualitative in nature with few examinations of prevalence: it focuses on the coach-athlete relationship, resulting in a lack of research on other members of the athletes' support system otherwise known as the 'entourage' and on peer athletes. The only large-scale study available is from the UK, which reported a prevalence of psychological abuse of $75 \%$, raising concerns that this may be the most urgent safeguarding concern in youth sport. ${ }^{38} 39$ Psychologically abusive behaviours described by athletes generally reflect those described by the WHO and the UN Convention on the Rights of Children. $^{35} \quad 38 \quad 40 \quad 41$ Athletes report: belittling, humiliating, shouting, scapegoating, rejecting, isolating and threatening behaviours as well as being ignored, or denied attention and support. $^{2426384243}$

Research findings indicate that the normalisation of psychologically abusive coaching practices, with a pervasive bystander effect, prevents disclosure and seeking of help. ${ }^{26} 4445$ This constitutes a risk for the delivery of safe sport and the prevention of other forms of abuse. Additionally, it appears that psychologically abusive coaching practices can facilitate and mask sexual abuse grooming behaviours. ${ }^{26}$

\section{Sexual harassment and abuse}

Sexual harassment and abuse in sport stem from abuses of power relations ${ }^{46} 47$ facilitated by an organisational culture that ignores, denies, fails to prevent or even tacitly accepts such problems. ${ }^{45} 48$ They may thus be considered as symptoms of failed leadership. Definitions are not universally agreed on, ${ }^{49} 50$ but broadly align with those displayed in box 1 .

Sexual harassment and abuse can be targeted at any athlete regardless of age, sport ability, gender, nationality, race or 
Box 1 Definitions adopted in the IOC Consensus

Statement

- Athletes with disabilities-Those who have long-term physical, mental, intellectual or sensory impairments that, in interaction with certain barriers, may hinder their full and effective participation in society on an equal basis with others. $^{19}$

- Bullying-Bullying (or cyberbullying if conducted online) is unwanted, repeated and intentional, aggressive behaviour usually among peers, and can involve a real or perceived power imbalance. Bullying can include actions such as making threats, spreading rumours or falsehoods, attacking someone physically or verbally and deliberately excluding someone.

- Child and adolescent-Every human being below the age of 18 years unless, under the law applicable to the child, majority is attained earlier. ${ }^{20}$ Early childhood relates to those below 8 years of age. Juvenile or young person and adolescents are 10-19 years of age. ${ }^{20}$

- Hazing-An organised, usually team-based, form of bullying in sport, involving degrading and hazardous initiation of new team members by veteran team members. $^{21} 22$

- Homophobia-Antipathy, contempt, prejudice, aversion or hatred towards lesbian, gay or bisexual individuals.

- Neglect-The failure of parents or care givers to meet a child's physical and emotional needs or failure to protect a child from exposure to danger. ${ }^{23}$ This definition equally applies to coaches and athlete entourages.

- Negligence-Acts of omission regarding athlete safety. For example, depriving an athlete of food/or drink; insufficient rest and recovery; failure to provide a safe physical training environment; or developmental age-inappropriate or physique-inappropriate training methods.

- Physical abuse-Non-accidental trauma or physical injury caused by punching, beating, kicking, biting, burning or otherwise harming an athlete. This could include forced or mandated inappropriate physical activity (eg, age-inappropriate or physique-inappropriate training loads; when injured or in pain); forced alcohol consumption; or systematic doping practices.

- Psychological abuse-A pattern of deliberate, prolonged, repeated non-contact behaviours within a power differentiated relationship. ${ }^{24}{ }^{25}$ This form of abuse is at the core of all other forms. Some definitions refer to emotional or psychological abuse interchangeably. In this document, we refer to psychological abuse in recognition that the psyche consists of more than emotions. It also consists of cognitions, values and beliefs about oneself, and the world. The behaviours that constitute psychological abuse target a person's inner life in all its profound scope.

- Safe sport-An athletic environment that is respectful, equitable and free from all forms of non-accidental violence to athletes.

- Sexual abuse-Any conduct of a sexual nature, whether non-contact, contact or penetrative, where consent is coerced/manipulated or is not or cannot be given. ${ }^{26-29}$

- Sexual harassment-Any unwanted and unwelcome conduct of a sexual nature, whether verbal, non-verbal or physical. ethnicity, social class, education level, sexual orientation or disability. ${ }^{51-54}$ Sexual harassment and abuse are perpetrated in all sports and at all levels, ${ }^{51} 55$ with prevalence of both forms higher in elite sport. ${ }^{12} 1349$ Prevalence rates in sport vary with sexual harassment ranging from $19 \%$ to $92 \%$ and sexual abuse from $2 \%$ to $49 \%$; this wide range of prevalence is due to differing measures and study designs. ${ }^{56-59}$ Sexual abuse is usually preceded by a 'grooming' process whereby the perpetrator prepares and desensitises their victim and entices them to submit. ${ }^{28} 29$ Athletes with disabilities and LGBT athletes are more likely to be at risk of experiencing sexual abuse. ${ }^{13}{ }^{60}$ Entourage members, in positions of power and authority, are often perpetrators of abuse, ${ }^{61}{ }^{62}$ but peer athletes are far more likely to be perpetrators of sexual harassment than are coaches. ${ }^{63-65}$ Males are more often perpetrators of sexual abuse than females, ${ }^{51}$ although reports of male athlete victimisation have challenged assumptions about the gender status of sexual abuse victims. ${ }^{64}$ 66-69

Risks of sexual abuse are greater when there is a lack of protection (such as safe sport policies, procedures or codes of practice), high perpetrator motivation and high athlete vulnerability (especially in relation to age and maturation as some perpetrators target young athletes). ${ }^{45} 70$ The amount of clothing cover, touching and sport type are not risk factors for sexual harassment or abuse. ${ }^{51}{ }^{71}$ Perpetrators commonly seek out oportunitites in less supervised environments. Athlete reports indicate that sexual abuse can occur in the locker room, the playing field, trips away, the coach's home or car and social events, especially where alcohol is involved. ${ }^{44} 7273$

\section{Physical abuse and forced physical exertion}

Physical abuse may be inflicted both on and off the field of play. It is often perpetrated by individuals in positions of power and trust, such as coaches and members of the athlete entourage, as well as family and friends, peer athletes and sports fans. ${ }^{4} 674$

Empirical data on the prevalence of physical abuse and forced physical exertion in sport are minimal, with much information resulting from public reporting of incidents. The 'win/lose' nature of sports and a culture of athlete idolisation results in a tacit acceptance or normalisation of many types of violence in sports. ${ }^{75-77}$ This applies especially to the physicality of contact sports, where the athlete's body is considered integral 'equipment'.

\section{Neglect}

Little research has been published on neglect in sport, particularly with respect to children and adolescents. However, there are many reports of sporting incidents resulting in preventable illness, injury or death where negligence, and breaches of health and safety legislation or guidance, are implicated. ${ }^{78}$

It is important to distinguish between the duty of care afforded to athletes under the age of 18 years and that afforded to adults. The physical impact of neglect may be greater on the developing young athlete who has unique physical, cognitive and psychological vulnerabilities. For instance, the consequences of exposure to extreme heat or provision of insufficient hydration during exertion may have serious health consequences. In addition, the child has unique nutritional demands to sustain growth and development. ${ }^{31}$

There are overlaps between neglect and failure to prevent overtraining and overuse injuries that may be categorised as physical abuse. Other forms of neglect in sport are the denial of access to appropriate medical care, and the failure to implement sport safety equipment and rules in the training and competition environments. ${ }^{79}$ All forms of abuse and neglect are underpinned by psychological maltreatment. Commodification of athletes as 
assets as opposed to rights bearers increases the risks of their individual physical and emotional needs being neglected. ${ }^{80}$

Indicators and consequences of neglect include preventable accidents and recurrent injuries, malnutrition, eating disorders, disordered eating, dehydration, mental health problems, psychological disorders, self-harming, long-term illness and secondary disability or death.

\section{MECHANISMS FOR HARASSMENT AND ABUSE}

A range of harassment and abuse mechanisms is evident in the sport context (figure 1), which provides specific mechanisms for such behaviour. These may be conceptually discrete but they frequently overlap in practice.

Contact mechanisms: Close proximity, frequent group interactions and rough-and-tumble handling are used by perpetrators as pretexts or platforms to perpetrate abuse, although touch per se has not been shown to be a risk factor. ${ }^{81}$

Non-contact/verbal mechanisms: A common form of harassment in sport is verbal harassment. ${ }^{64}$ Few studies distinguish between non-sexual and sexual verbal harassment. Prevalence of verbal harrassment varies from $18 \%{ }^{82}$ to $78 \%{ }^{64}$ Peers are often reported to be perpetrators of verbal harassment. ${ }^{64}$ Trash talk (or 'sledging') is a form of verbal harassment from athlete opponents or fans that is intended to destabilise athlete motivation and to hinder performance. There are few studies on this issue. $^{83} 84$

Cyber mechanisms: An estimated 92\% of teenagers are online daily. ${ }^{85}$ This accessibility provides another platform through which bullying, harassment and abuse may be planned and perpetrated. ${ }^{86} 87$ The increased use of 'smart' devices, together with the prevalence of social media use among young people, potentially exposes victims to a non-stop ' $24 / 7$ ' bombardment of unwanted content. As with other forms of bullying, harassment and abuse, the impact of cyberbullying ranges from upset and distress, to self-harm and suicide. ${ }^{88-91}$

Cyber harassment and abuse comes in a variety of forms: ${ }^{86-89}$ 91-95

- Grooming of young people with a view towards sexual abuse (online and real world) being perpetrated. This may involve contact from individuals who are not known to the child or young person in their day-to-day life.

- Sending or receiving sexual messages or images, known as 'sexting'.

- Use of camera phones to take illicit photographs, including inside sports facilities (particularly changing rooms) and use of the images for sexual exploitation (sometimes called 'sextortion'). ${ }^{96}$

- Receiving unwanted negative content such as hate messages, exposure to sexual and violent content, and proself-harm or proeating disorder/body dysmorphia sites.

- Risks to an individual's reputation from sharing of inappropriate content and/or from creation of false online profiles and impersonation of an individual.

- Grooming of young people with a view to perpetuate corruption (online and real world) for match fixing and associated activities, which may breach sports' integrity rules and/or constitute criminal offences.

- Theft of personal and identity data, which may constitute a criminal offence.

There is little research into the prevalence of cyber harassment and abuse in sport; but there is evidence that athletes increasingly use social media to communicate with fans and to promote their image, ${ }^{97} 98$ and are subject to online abuse. ${ }^{93} 94$ There are criminal cases of online harassment and abuse involving athletes, ${ }^{99}$ and some organisations have implemented policies and education to address this risk in sport. ${ }^{92} 100101$ Much of the research that is available concerns risks to children and young people, such as the European Union Kids Online study. 89

Negligence: There is overlap between negligence and the failure to prevent overtraining and overuse injuries as well as the deprivation of athlete access to food, drink or medical care, which might also be categorised as physical abuse. As described above, all forms of abuse and neglect are underpinned by psychological maltreatment. Commodification of athletes as assets as opposed to rights bearers increases the risks of their individual physical and emotional needs being neglected. ${ }^{80}$

Bullying: Bullying involves a desire to hurt through a harmful action in a context of a power imbalance. ${ }^{102}$ Typically, bullying is repetitious with evident enjoyment by the aggressor and generally a sense of being oppressed on the part of the victim. Examples of bullying include insults or taunts, physical intrusions (pinching, punching), refusing to engage with or 'pass the ball/puck' to an athlete, humiliation, social exclusion or threats. There are different ways of classifying bullying. The first includes direct and indirect behaviour. ${ }^{103}$ Direct bullying involves open attacks on a victim and indirect bullying is distinguished by social isolation, exclusion from a group or nonselection for activities. A second way of classifying bullying is to divide the behaviour into the following three groups: psychological bullying, social bullying and physical bullying. ${ }^{104}$ Psychological bullying can be verbal, such as ridicule, threatening, name calling etc, or it can be non-verbal, such as using body language, which could include turning one's back towards someone. Social bullying can include consciously ignoring a person. Physical bullying can be body contact such as physically beating the victim or destroying clothes or other property. There are few studies of bullying in sport but, according to True Sport, 30\% of youth report experiencing bullying. ${ }^{105-107}$

Hazing: Hazing is widespread in North America and is increasingly recognised as a sport problem elsewhere. ${ }^{108} 109$ Hazing is usually a normative requirement of acceptance into a club or team and part of a rite of passage handed down semicovertly from one sport generation to the next, sometimes in the presence of coaches. ${ }^{110-112}$ Female athletes are increasingly copying the traditions of male hazing in sport. ${ }^{113} 114$

Many hazing practices at team initiations or start/ end-of-season celebrations involve extreme insults, feats of endurance, deprivation, alcohol consumption and promiscuous or illegal sexually explicit/abusive behaviour against individuals or groups. ${ }^{115}$ Whereas bullying often deters sport participation, hazing is intended to increase commitment and is regarded as the price of team membership. Both bullying and hazing involve a form of moral disengagement that facilitates and reinforces antisocial rather than prosocial behaviour. ${ }^{116-118}$

Sport cultures that haze are characterised by misogyny and homophobia, tolerance of exclusion, misconduct and discrimination, lack of mutual respect and pride, and by enforced silence to protect group secrets about abuse. ${ }^{119}$ The secrecy surrounding hazing makes it difficult to measure and quantify. Ethnographic studies provide some qualitative accounts ${ }^{109} 120$ but, by its very nature, it is rare for victims of hazing to speak out, and thus unusual for medical staff and other entourage members to become involved in evaluation or support.

\section{CHILD AND ADOLESCENT ATHLETES}

Every child has the 'right to participate fully in play and recreation activities ${ }^{20}$ and to do so in a safe, welcoming and 
respectful environment. ${ }^{31}$ However, some risks to young athletes are unique to sport, such as the coach-athlete relationship, intensity of sport practice and the demands of competition, media interest in child athletes, athlete recruitment practices, relocation of minors to a distant training facility, practices requiring physical measurement and biological passports, varied training locations and times, separation from family or school communities due to sports participation, sport initiation and hazing practices. Policies with respect to children in sport are outlined in the International Safeguards for Children in Sport. ${ }^{121}$ According to the WHO, adolescence is a critical transition period that is also characterised by high sport participation. ${ }^{122}$ Young athletes are more vulnerable to abuse at this time because of their need to be cared for, protected and supervised during their development. ${ }^{31}$ Jurisdictional vulnerability arises because of wide variations in ages of consent across regions and countries, ${ }^{123}$ and variations in religious and ethnic customs and practices. 124

The coach-athlete relationship has been the focus of a number of abuse studies, with many cases concerning child or adolescent athletes. ${ }^{4466}$ Children in sport may also be subject to violence perpetrated against them by coaches, members of the entourage and peer athletes. Children can experience all forms of harms including psychological, sexual, and physical harassment and abuse, as well as neglect implemented through the same mechanisms experienced by adult athletes. Importantly, the concept of consent cannot apply to children and thus cannot be used in mitigation by perpetrators of abuse. ${ }^{125}$

\section{ATHLETES WITH A DISABILITY}

Approximately $15 \%$ of the world's population is made up of individuals with disabilities of whom about $80 \%$ live in developing countries with attendant concerns about inequities and exclusion. ${ }^{126}$ Experts conservatively estimate that people with disabilities are at least four times more likely to be victimised than people without disabilities: ${ }^{127}$ those individuals with an intellectual impairment are at the highest risk. ${ }^{128}$ The number of victimised children with disabilities is estimated at 31\% compared with $9 \%$ of non-disabled children. ${ }^{129}$ Data from sport confirm that youth athletes with disabilities experience a two to three times increased risk of psychological, physical and sexual abuse and harassment when compared with youth athletes in general. ${ }^{13}$

In sport, disability is an evolving concept, one which results from interaction between those with impairments and the barriers to their full and effective sport participation. ${ }^{130}$ As opportunities expand for athletes with disabilities to pursue their athletic endeavours, there is a pressing need to understand the nature of individual development and how participation can be enhanced or inhibited for persons with sensory, intellectual or physical impairements. There is also a need for sport to align its operations more closely with Article 30.5 of the UN Convention on the Rights of Persons with Disabilities, which directly outlines the right to sport participation as a critical element of social inclusion more broadly. ${ }^{19}$

In addition to the general risks outlined in this paper, specific vulnerabilities to non-accidental violence or intentional harm for athletes with disabilities relate to (1) making uninformed assumptions about the care needs of athletes, (2) exploiting the athletes' dependence on personal care (eg, communication requirements, travel requirements and competition logistics), and (3) blurring of the roles and responsibilities in the coachathlete relationship, ${ }^{131}$ and, where present, the caregiver-athlete relationship. ${ }^{60121132}$

\section{LESBIAN/GAY/BISEXUAL/TRANS-SEXUAL ATHLETES}

Homosexuality is a crime in approximately 70 countries. ${ }^{133}$ Punitive laws in various countries (eg, Russia, Uganda) ban 'propaganda of non-traditional sexual relations', outlaw homosexuality or ban same-sex relationships. ${ }^{133}$ In the first large-scale international study on homophobia in sport, Denison and Kitchen ${ }^{107}$ report that $80 \%$ of the 9500 respondents witnessed or experienced homophobia in sport. Homophobia can be expressed institutionally as part of the sporting culture through, for example, employment conditions, ${ }^{107}{ }^{134}$ team selection, career length, ${ }^{135} 136$ and inequality and disrespect in the sport environment. ${ }^{134}$

Homophobia harms those discriminated against, those who participate in a homophobic sport environment and those who leave sport because of it. ${ }^{134} 137$ Cashmore and Cleland ${ }^{138}$ report that, in English football, 'fans habitually use gay epithets to abuse players'. Sheldon Kennedy, who was repeatedly sexually abused by his coach when a junior Canadian professional hockey player said that he was afraid to disclose his abuse because he thought people might think he was gay. ${ }^{139}$ Denison and Kitchen ${ }^{107}$ found that the acceptance of LGB in six participating countries was $22.9 \%$. Acceptance was defined as: LGB respondents who were 'out' reported it to their entire team, did not witness or experience homophobia, held positive views on safety of LGB with spectators, believed youth sport was supportive and safe for LGB people, and believed LGB people were accepted.

\section{IMPACTS OF NON-ACCIDENTAL VIOLENCE Impact on athletes}

The personal costs of non-accidental violence to athletes can be long term and extremely damaging (see figure 1). ${ }^{140}$ The impact of such experiences extends to affect family, friends, colleagues and peers in home, work and leisure venues. The impacts can persist long after the athlete has left his or her sport role. ${ }^{141}$ Non-accidental violence in sport can also have serious negative impacts on athletes' physical, social and psychological health (see figure 1). ${ }^{26} 142-144$ The various abuses described above may impair performance, be associated with doping, increase athletes' willingness to cheat, lead to athlete drop-out or result in a variety of presentations including psychosomatic illnesses, disordered eating, anxiety, depression, substance abuse, self-harm and even suicide. ${ }^{36} 72143145146$

Psychological abuse can impair long-term physical and psychological health, affecting personal and social development. ${ }^{147-149}$ Harmful deficits in self-esteem and a range of related problems, such as eating disorders, ${ }^{150} 151$ self-harm, suicide, somatic illnesses and detriments to academic performance, have been reported in the mental health literature. ${ }^{152}$ Sport research similarly identifies that athletes self-report feelings of anxiety and depression, low self-esteem, poor body image $^{25}$ and, ultimately, dropping out of sport. ${ }^{3842} 43$ Relative to sexual and physical abuse, childhood psychological abuse has been found to be the more powerful correlate of long-term post-traumatic and dissociative symptomatology among athletes. $^{36}$

The potentially devastating effects of physical violence include physical injury; death; developmental delays; other organic health problems; mental illnesses; and social, emotional and cognitive impairment. ${ }^{4} 631$ 153-155 ${ }^{6}$ Pysical consequences are especially serious for child or adolescent athletes due to the growth and maturation processes associated with their stage of life. $^{31} 155-157$ 
Childhood sexual abuse in the non-sport population is a strong predictor of non-suicidal self-injury/self-harm and suicide attempts subsequent to the abuse. ${ }^{158}$ Harassment of any type, particularly sexual harassment, has been linked to a variety of poor mental health and well-being outcomes, including selfharm, among adolescents. The risk of non-suicidal self-injury/ self-harm, suicide attempts and completed suicide increases with the number of harassment types that an adolescent experiences. ${ }^{159}$ Early detection and intervention, which reduces the incidence of harassment, is particularly important in mitigating mental health difficulties and behavioural self-harm among adolescents. ${ }^{160}$ Other physical impacts of sexual abuse include sexually transmitted illnesses, urogenital and anogenital trauma, and unwanted pregnancy.

In addition to the health effects listed in the paragraphs above, many athlete victims of non-accidental violence suffer performance detriments, opportunity costs, reduced medal chances and loss of sponsorship. ${ }^{45}$ Non-accidental violence has also been associated with doping and an increase in willingness to cheat. ${ }^{146}$ Some choose to change or even to quit their sport, and others suffer personal consequences for years. ${ }^{143}$

Athletes are frequently silenced by the harassment and abuse process. $^{48} 161$ In addition, passive attitudes/non-intervention, denial or silence by people in positions of power in sport (particularly bystanders) and lack of formal accountability all create the impression for victims that such behaviours are legally and socially acceptable, and that those in sport are powerless to speak out against them: this bystander effect can compound the initial psychological trauma. ${ }^{45} 62162163$ Athlete survivors of non-accidental violence may conceal their distress to maintain their position on the team or to preserve anonymity. The interaction of perpetrator methodology, silencing, isolation, bystander inaction, organisational denial and powerlessness also contribute to athlete non-disclosure. Certain organisations, especially in the education sector, have made strenuous efforts to control or eliminate such problems (see below). Nevertheless, the prevalence data reported above indicate that these issues have a strong cultural grip on sport. Despite this, many survivors recover to a positive state of mental health and resume normal lives, including sport roles.

\section{Impact on sport}

From an organisational perspective, the impacts of harassment and abuse represent asset depreciation. The economic impact of non-accidental violence to athletes on sport organisations is also considerable (see figure 1). When athlete disaffection resulting from harassment or abuse leads to drop-out/attrition, this represents not just a loss of potential medals but also an opportunity cost for sport organisations, the talent pool of which consequently gets depleted. Further, the reputational damage caused by adverse publicity of cases of harassment or abuse sometimes leads to the termination of sponsorship contracts. ${ }^{45}$ It also undermines the confidence and trust that athletes, their entourages, families and fans place in sport administrators.

The cost-benefit analysis of harassment and abuse versus prevention has yet to be demonstrated in detail in the way that, for example, health economics has been applied to illness treatment versus prophylactic work. As legal redress becomes pursued more frequently by athlete victims, it is likely that the sport community will realise the overall asset depreciation effect of this problem. Certainly, a comparison could be made to issues of performance enhancing drug abuse in sport. It is important to note that prevalence data for antidoping rule violations indicate that abuse and harassment is a more widespread challenge to the elite sport community. ${ }^{1364164165}$

\section{PREVENTION OF HARASSMENT AND ABUSE}

In the face of validated research indicating that harassment and abuse in sport is serious and widespread, the promotion of safe sport is an urgent task. ${ }^{67} 101{ }^{166-172}$ Indeed, the prevention of harassment and abuse is increasingly constructed and presented as a public health concern, linking population and community health, to personal health and welfare. ${ }^{173}$

Eliminating non-accidental violence against athletes is also part of a broader international conversation in sport addressing ethical and integrity issues, such as doping, match manipulation, event security and fair play. ${ }^{39}$ 174-182 This focus reflects a wider societal discourse regarding abusive and unethical practices in institutional settings, such as the church, healthcare and the military, igniting public interest in the prevention of abuse more broadly, and highlighting the importance of rigorous safe sport business practices. ${ }^{183} 184$

To reduce tolerance and prevent abuses, a systematic multiagency approach is most effective. ${ }^{4} \quad 6 \quad 185 \quad 186$ This includes reviews of law enforcement strategies, culturally tailored education for athletes, parents, athlete entourage, fans, sponsors and sports administrators, and implementation of policy and procedures within the sports community. Any initiative aiming to prevent harassment and abuse should take into account the particular cultural context of the country and the sport.

Educated, ethical entourage members are key to the performance success of athletes. ${ }^{155}$ First responders, such as medical personnel, are also critical in identifying and referring athletes for further healthcare as indicated, and in influencing policy change by sports management. ${ }^{31} 153-155$

As part of this effort, personnel should avoid commodifying athletes at the expense of their human rights, since this will ultimately undermine athlete-and thus sport-integrity and security. ${ }^{187} 188$ Sport personnel involved in athlete development and performance have a particular responsibility to operate within professional boundaries, to understand, identify and refer signs of harassment and abuse, and to mitigate associated risks. ${ }^{18}$ Yet ignorance, denial and resistance among sports leaders-and even athletes themselves-is often a challenge to risk mitigation and prevention. Understandably, they may be reluctant to acknowledge that harassment and abuse occur in their organisations. ${ }^{45} 189$ Denial allows the underlying causes of harassment and abuse to persist, and the interpersonal correlates of these behaviours to proceed unchecked; thus, it is critical to build and disseminate awareness of the widespread and serious nature of abuse, and its consequences, including health or medical implications.

Unless specially trained and qualified in this field, entourage members should not attempt to evaluate or treat athletes alleging harassment or abuse but should refer all disclosures to relevant experts in social work, counselling or medicine, for further physical and/or psychological investigation and treatment. ${ }^{79}$ Allegation investigation should be referred to the relevant resources in the community. If criminal activity directed towards a minor is suspected, then it is also necessary to involve law enforcement agencies as soon as possible. However, while nonaccidental violence often manifest as health or medical issues, the context in which they arise is social and these social factors should therefore be addressed, in the first instance, through prevention efforts. To avoid an overly narrow focus on the psychopathological aspects of these problems it is important for sport stakeholders to understand wider societal risk factors for 
harassment and abuse. These include the power imbalances associated with hierarchical and heteronormatively masculine authority systems of sport that lead to a culture of secrecy and deference that facilitates abuse. ${ }^{4859} 190$ Power imbalances may also lead to intense selection rivalries among peer athletes, which can result in both prosocial and antisocial behaviours.

Cultural change can be effectively addressed via advocacy and campaigning. ${ }^{180} 191$ Accepted structural components of safe sport programmes that address the social context of abuse and harassment include clear policies with associated codes of practice; systematic recruitment and background screening; education and training; complaint and support mechanisms; and monitoring and evaluation systems. 613170179 192-199

Education should be the cornerstone of any safe sport strategy. Indeed, prevention begins with awareness-raising about nonaccidental violence through the dissemination of evidence-based education and training programmes. This provides stakeholders with the understanding and knowledge both to overcome denial and to implement prevention solutions. All levels of the organisation need to be targeted, from international sport executives to local volunteers, including athletes, ${ }^{196} 200201$ athlete entourage members (coaches, agents, fitness personnel), ${ }^{202-209}$ administrators and sport managers, ${ }^{171}{ }^{210-216}$ families and peers, ${ }^{199} 217218$ clinicians and healthcare providers, ${ }^{153} 163219220$ and sport and exercise science professionals and their training agencies. ${ }^{154} 221-224$

Ownership of harassment and abuse by leaders within a sport organisation is a vital prerequisite for effective prevention since it sets the tone of acceptance and responsibility necessary to facilitate desired, healthy cultural change. ${ }^{191} 225226$ 'Safe sport' (see box 1) should be appropriately incorporated as a core element of a robust business model in sport or good governance $^{227}$ with advocacy essential from the top down in every sport organisation. Structural changes that share power and decision-making with athletes-institutionally, organisationally and personally - are important steps towards risk mitigation. ${ }^{180}$

The primary building blocks for safe sport include culturally specific policy and procedures, with implementation, monitoring and evaluation systems. Some organisations have clearly mandated standards, progress measures, monitoring and sanctions to promote accountability, and minimise power imbalances. $^{92} 168196$ These may be functionally connected to the criminal justice system through which legal redress can be sought and/or they are linked to government funding of the sport itself (eg, in the UK). ${ }^{121}$ Disciplinary, grievance and dispute resolution procedures may be available inside a sport governing body or, alternatively, accessed through generic or shared mechanisms. ${ }^{197} 228$ Where no internal safe sport system is in place, organisations should consider working with relevant social care and criminal justice mechanisms to develop their own safe sport awareness, understanding and practices. ${ }^{191} 220$

\section{SUMMARY AND RECOMMENDATIONS FOR ACTION}

The evidence set out above demonstrates the urgency with which sport authorities need to develop and implement clear and effective remedies for all types of non-accidental violence against athletes. It also undermines the prevailing assumption 'that teams are exemplary sites for human interaction'. ${ }^{229}$ Sport, like all other social institutions, is no stranger to harassment and abuse, yet it has been slow to develop appropriate responses and prevention programmes.

Ever since the first Consensus Statement on Sexual Harassment and Abuse was issued by the IOC, there has been exponential growth in public disclosures, and awareness of cases of harassment and abuse against athletes. All ages and types of athletes are susceptible to these problems; however, science has confirmed that the risks are highest among elite, disabled, child and LGBT athletes, and that psychological abuse is at the core of all other forms. As well as being victims, athletes can also be perpetrators. The sociocultural precursors of harassment and abuse are based on entrenched prejudices that are expressed through power differences, and use a range of interpersonal mechanisms.

Much more research is needed to protect athletes of all ages and impairments. ${ }^{121}$ Such research should include prevalence of all forms of non-accidental violence in countries for which there are currently no data; the gendered nature of violence; mechanisms of disclosures and responses to violence; violence prevention methods; safe sport advocacy and effectiveness (what works, from team selection to postgames review); and athlete consultation methods. However, action to ensure safe sport need not wait for these studies. Everyone involved in sport, not least the athletes themselves, will benefit from 'safe sport'. It is incumbent on all stakeholders in sport to adopt general principles for safe sport ${ }^{101} 169170$ as well as to implement the following recommendations without delay in a culturally respectful and sensitive manner.

\section{Sport organisations}

1. Implement and monitor policies and procedures for safe sport that: ${ }^{171}$

- State that all athletes have a right to be treated with respect, protected from non-accidental violence;

- State that the welfare of athletes is paramount;

- Identify who has responsibility for implementation;

- Specify what constitutes a violation and specify the range of consequences;

- Detail a response system for handling athlete/whistleblower concerns and complaints, with reporting and referral mechanisms and a neutral resolution mechanism;

- Provide details of where to seek advice and support for all parties involved in a referral or complaint.

2. Deliver an education programme for all main stakeholders about how to engage in the practicalities of preventing nonaccidental violence to athletes.

3. Appoint or work with qualified, designated personnel responsible for safe sport programming and athlete welfare.

4. Listen to the voices of athletes in decision-making about their own protection.

5. Foster strong partnerships with athletes' parents/caregivers to promote safe sport.

6. Partner with expert groups and stakeholders to follow a systematic multidisciplinary, multiagency approach. This may include law enforcement, media, medical, child protection, counselling and support or other groups.

\section{Athletes}

7. Know your rights and responsibilities with regard to the prevention and reporting of non-accidental violence.

8. Identify your support systems among and beyond entourage members.

9. Support your peers and encourage them to speak out if they witness or experience non-accidental violence.

10. Negotiate for a voice in decision-making about your own protection.

Sports medicine and allied health practitioners

11. Ensure that you are adequately trained to: 
i. Recognise the signs and indicators of non-accidental violence;

ii. Effectively and appropriately respond to disclosures of non-accidental violence.

12. Ensure that you have access to a multidisciplinary professional support team prior to initiating any treatment plan for athletes who are survivors of non-accidental violence.

13. Know where and how to refer disclosures or suspicions.

\section{Sport science researchers}

14. Grow the scientific evidence base about the prevalence, incidence and prevention of non-accidental violence to athletes.

15. Engage in and promote knowledge transfer to apply scientific findings to 'real-life' sport settings.

The enormous cultural power of the major sport agencies (eg, IOC, International Paralympic Committee, International Federations and National Olympic Committees, among others) offers them an opportunity to demonstrate leadership by implementing these recommendations. This, in turn, should both prevent non-accidental violence against athletes and embed a safe, welcoming and respectful sport environment for all.

\section{Author affiliations}

${ }^{1}$ Department of Family Medicine, Michael G. DeGroote School of Medicine, McMaster University, Hamilton, Ontario, Canada

${ }^{2}$ FINA Sports Medicine Committee, Lausanne, Switzerland

${ }^{3}$ University of Brunel, London, UK

${ }^{4}$ United States Oympic Committee, Colorado Springs, Colorado, USA

${ }^{5}$ Harvard University, Boston, Massachusets, USA

${ }^{6}$ General Counsel Workplace Options LLC, Raleigh, North Carolina, USA

${ }^{7}$ Department of Social and Cultural Studies, Norwegian School of Sport Sciences, Oslo, Akershus, Norway

${ }^{8}$ University of Winnipeg, Winnipeg, Manitoba, Canada

${ }^{9}$ Hong Kong Sport Institute, Hong Kong

${ }^{10}$ Department of Psychiatry, University of Toronto, Toronto, Ontario, Canada

${ }^{11}$ Womens Tennis Association, St Petersburg, Florida, USA

${ }^{12}$ International Tennis Federation, London, UK

${ }^{13}$ Safe4Athletes, Los Angeles, California, USA

${ }^{14}$ Child Protection in Sport Unit, National Society for the Prevention of Cruelty to Children, London, UK

${ }^{15}$ IOC Medical and Scientific Department, Lausanne, Switzerland

\section{Twitter Follow Sandi Kirby at @s.kirby@uwinnipeg.ca}

Acknowledgements The $I O C$ authors wish to acknowledge the $I O C$ Working Group on the Prevention of Harassment and Abuse in sport for their supportive attendance and valuable contributions at the Consensus meeting as well as to the editing of the final document. Most importantly, the authors wish to thank this IOC Working Group for their leadership and advocacy activities aimed at promoting safe sport, free from harassment and abuse for all participants (Prince Feisal Al-Hussein and Andrea Carksa-Sheppard-IOC Women and Sport Commission; Dr Margo Mountjoy-10C Medical Commission; Pedro Yang- $10 \mathrm{C}$ Entourage Commission and IOC Athletes' Commission; Dr Cheri Blauwet-IPC Medical Commission). A special thanks to Sebastian Cruz for assistance with final editing.

Contributors $\mathrm{MM}$ and $\mathrm{CB}$ are first authors, and provided substantial contributions to conception and design, co-coordinators of IOC Expert Group+Consensus meeting, drafting and revising the manuscript, and approving the final version to be published. MA, KF, SK, TL, SM, KM and KS are members of IOC Expert Group and contributors at Consensus meeting, and provided substantial contribution to drafting and final revision of the manuscript to be published. CB and AC-S are members of IOC Working Group and participants at Consensus meeting, and were involved in final revision of the manuscript to be published. AT is member of IOC Expert Group and contributor at Consensus meeting, and was involved in final revision of the manuscript to be published. RB is the Director IOC Medical and Scientific Department and participant at Consensus meeting, and was involved in final revision of the manuscript to be published.

Funding The Consensus meeting was funded by the IOC

Competing interests None declared.

Provenance and peer review Not commissioned; externally peer reviewed

\section{REFERENCES}

1 Drinkwater BL. The encyclopaedia of sports medicine: an IOC Medical Commission publication. Lausanne, Switzerland: International Olympic Committee Medical Commission, 2008

2 Harris JD, Cvetanovich G, Erickson BJ. Current status of evidence-based sports medicine. Arthroscopy 2014;30:362-71.

3 Brackenridge $\mathrm{CH}$. Violence and abuse prevention in sport. In: Walsh $\mathrm{K}$, Zwi $\mathrm{K}$, ed. The prevention of sexual violence: a practitioners' sourcebook. Holyoke, MA NEARI Press, 2010:401-13.

4 Brackenridge $\mathrm{CH}$, Fasting $\mathrm{K}$, Kirby S, et al. Protecting children from violence in sport; a review from industrialized countries. Florence: UNICEF Innocenti Research Centre, 2010.

5 Education NAfSaP. Physical activity used as punishment and/or behavior management: position statement. Reston, VA, USA: 2009.

6 ICES. Safeguarding youth sport: stimulating the individual empowerment of elite young athletes and a positive ethical climate in sport organisations. Belgium: International Centre for Ethics in Sport, 2015.

7 Wilsher K. The pushy tennis dad and the drugs in the drink. The Guardian, 2006.

8 Brackenridge $\mathrm{CH}$, Rhind D. Child protection in sport: reflections on thirty years of science and activism. Soc Sci 2014;3:326-40.

9 Timpka $T$, Finch $C F$, Goulet $C$, et al. Meeting the global demand of sports safety: the intersection of science and policy in sports safety. Sp Med 2008;38:795-805.

10 Vanden Auweele EY. Challenging modern sports' moral deficit; towards fair trade, corporate social responsibility and good governance in sport. J Commun Health Sci 2010;5:1-9.

11 Fasting $\mathrm{K}$, Brackenridge $\mathrm{CH}$, Miller $\mathrm{KE}$, et al. Participation in college sports and protection from sexual victimization. Int J Sp Exerc Psychol 2008;6:427-41.

12 Fasting $\mathrm{K}$, Brackenridge $\mathrm{CH}$, Knorre N. Performance level and sexual harassment prevalence among female athletes in the Czech Republic. Women Sport Phys Act $J$ 2010;19:26-32.

13 Vertommen T, Schipper van Veldhofen NS, Hartill MJ, et al. Sexual harassment and abuse in sport: the NOC NSF Helpline. Int Rev Sociol Sport 2015:50: 822-39.

14 Douglas K, Carless D. Life story research in sport: understanding the experiences of elite and professional athletes through narrative. London, UK: Routledge, 2014

15 IOC. Olympic charter: in force as from 2 August 2015. Lausanne, Switzerland: International Olympic Committee, 2015.

16 Stirling AE. Definition and constituents of maltreatment in sport: establishing a conceptual framework for research practitioners. Br J Sports Med 2009;43:1091-9.

17 Mountjoy M, Sundgot-Borgen J, Burke L, et al. The IOC consensus statement beyond the female athlete triad-Relative Energy Deficiency in Sport (RED-S). $\mathrm{Br}$ J Sports Med 2014:48:491-7.

18 Ljungqvist A, Mountjoy M, Brackenridge $\mathrm{CH}$, et al. IOC Consensus Statement on sexual harassment \& abuse in sport. Int J Sport Exerc Psychol 2008;6:442-9.

19 UNCRPD. United Nations convention on the rights of persons with disabilities: resolution adopted by the general assembly. New York, NY, USA: United Nations, 2007

20 UNCRC. United Nations convention on the rights of the child: resolution adopted by the general assembly. Geneva, Switzerland: United Nations, 1989.

21 Johnson J, Holman M. Making the team: inside the world of sport initiations and hazing. Toronto, Canada: Canadian Scholars' Press, 2004

22 Crow R, Macintosh EW. Conceptualizing a meaningful definition of hazing in sport. Euro Sp Mg Quart 2009;9:433-51.

23 Pinheiro PS. World report on violence against children. Geneva, Switzerland: United Nations, 2006

24 Stirling $A E$, Kerr GA. Defining and categorizing emotional abuse in sport. Eur J Sport Sci 2008;8:173-81.

25 Stirling AE, Kerr GA. The perceived effects of elite athletes' experiences of emotional abuse in the coach-athlete relationship. Int I Sp Exerc Psychol 2013;11:87-100.

26 Leahy T, Pretty G, Tenenbaum GA. Perpetrator methodology as a predictor of traumatic symptomatology in adult survivors of childhood sexual abuse. J Interpers Viol 2004;19:521-40.

27 Johansson S. Coach-athlete sexual relationships: if no means no does yes mean yes? Sport Educ Soc 2013;18:678-93.

28 Brackenridge $\mathrm{CH}$, Fasting K. The grooming process in sport. Biography 2005; 13:33-52

29 Owton H, Sparkes A. Sexual abuse and the grooming process in sport: learning from Bella's story. Sport Educ Soc 2015. (In press).

30 Mountjoy M, Armstrong N, Bizzini L, et al. IOC consensus statement: "training the elite child athlete". Br J Sports Med 2008;42:163-4.

31 Bergeron M, Mountjoy M, Armstrong N, et al. International Olympic Committee consensus statement on youth athletic development. Br J Sports Med 2015:49:843-51.

32 David P. Human rights in youth sport: a critical review of children's rights in competitive sport. London, UK: Routledge, 2005. 
33 Giulianotti R, McArdle D. Sport, civil liberties and human rights. London, UK: Routledge, 2006.

34 Brackenridge CH, Kay T, Rhind D, eds. Sport, children's rights and violence prevention: a sourcebook on global issues and local programmes. London, UK: Brunel University Press, 2012.

35 Krug EG, Mercy JA, Dahlberg LL, et al. The world report on violence and health. Lancet 2002;360:1083-8.

36 Leahy T, Pretty G, Tenenbaum GA. Contextualized investigation of traumatic correlates of childhood sexual abuse in Australian athletes. Int I Sp Exerc Psychol 2008:6:366-84.

37 Hart S, Binggeli NJ, Brassard MR. Evidence for the effects of psychological abuse. J Emotional Abuse 1998;1:27-58.

38 Stafford A, Alexander K, Fry D. 'There was something that wasn't right because that was the only place I ever got treated like that': children and young people's experiences of emotional harm. Childhood 2015;22:121-37.

39 Mountjoy M, Rhind DJA, Tivas A, et al. Safeguarding the child athletes in sport: a review, a framework and recommendations for the IOC youth athlete development model. Br J Sports Med 2015;49:883-6.

40 UNCRC. Optional protocol on the convention of the rights of the child on a communications procedure: adopted by the general assembly. Geneva, Switzerland: United Nations, 2011., 2011.

41 Raakman R, Dorsch K, Rhind D. The development of a typology of abusive coaching behaviours within youth sport. Int I Sports Sci Coach 2010;4:503-15.

42 Gervis M, Dunn N. The emotional abuse of elite child athletes by their coaches. Child Abuse Rev 2004;13:215-23.

43 Pinheiro MC, Pimenta N, Resende R, et al. Gymnastics and child abuse: an analysis of former international Portuguese female artistic gymnasts. Sport Educ Soc 2014:19:435-50.

44 Kirby SL, Greaves L, Hankivsky O. The dome of silence: sexual harassment and abuse in sport. London, UK: Zed Books, Ltd., 2000.

45 Brackenridge CH. Spoilsports: understanding and preventing sexual exploitation in sport. London, UK: Routledge, 2001.

46 Mewett $\mathrm{P}$, Toffoletti K. Rogue men and predatory women: female fans' perceptions of Australian Footballers' sexual conduct. Int Rev Sociol Sport 2008:43:165-80.

47 Tomlinson A, Yorganci I. Male coach/female athlete relations: gender and power relations in competitive sport. J Sport Soc Issues 1997;21:134-55.

48 Hartill M. Concealment of child sexual abuse in sports. Quest 2013;65:241-54.

49 Leahy T, Pretty G, Tenenbaum GA. Prevalence of sexual abuse in organised competitive sport in Australia. J Sex Aggress 2002;8:16-36

50 Timpka T, Janson S, Jacobsson J, et al. Protocol design for large- scale cross-sectional studies of sexual abuse and associated factors in individual sports: feasibility study in Swedish athletics. J Sports Sci Med 2015;14:179-87.

51 Fasting $\mathrm{K}$, Brackenridge $\mathrm{CH}$, Sundgot-Borgen J. Prevalence of sexual harassment among Norwegian female elite athletes in relation to sport type. Int Rev Sociol Sport 2004;39:373-86

52 Hartill M. Exploring narratives of boyhood sexual subjection in Male-sport. Sociol Sport J 2014;31:23-43.

53 Rintaugu EG, Kamau J, Amusa LO, et al. The forbidden acts: prevalence of sexual harassment among university female athletes. Afr J Phys Health Educ Recreat Dance 2014;20:974-90.

54 Gunduz N, Sunay H, Koz M. Incidents of sexual harassment in Turkey on elite sportswomen. Sport J 2007;10:1-10.

55 Timpka T, Janson S, Jacobsson J, et al. Lifetime sexual and physical abuse among elite athletes: a cross-sectional study of prevalence and correlates with athletic injury. Br J Sports Med 2014;48:667.

56 Chroni S, Fasting K. Prevalence of Male sexual harassment among female sports participants in Greece. Inquiries Sport Phys Educ 2009;7:288-96.

57 Baker TA, Byon KK. Developing a scale of perception of sexual abuse in youth sports (SPSAYS). Meas Phys Educ Exerc Sci 2014;18:31-52.

58 Fasting K. Assessing the sociology of sport: on sexual harassment research and policy. Int Rev Sociol Sport 2015;50:437-41.

59 Brackenridge $\mathrm{CH}$, Fasting K. Sexual harassment and abuse in sport: the research context. J Sex Aggress 2002;8:3-15.

60 Kirby SL, Demers G, Parent S. Vulnerability/prevention: considering the needs of disabled and gay athletes in the context of sexual harassment and abuse. Int I Sp Exerc Psychol 2008;6:407-26.

61 Toftegaard Nielsen J. Idrættens Illusoriske Intimitet (The Illusion of Sport Intimacy) [Doctoral Thesis]. In press, 2004.

62 Sand T, Fasting K, Chroni S, et al. Coaching behavior: any consequences for the prevalence of sexual harassment? Int I Sports Sci Coach 2011:6:229-42.

63 Elendu I, Umeakuka OA. Perpetrators of sexual harassment experienced by athletes in southern Nigerian Universities. S Afr I Res Sport Phys Edu Recreation 2011:33:53-64.

64 Fasting K, Huffman D, Sand TS. Gender based violence in Zambian sport: prevalence and protection. Oslo, Norway: Norwegian Olympic and Paralympic Committee and Confederations of Sports, 2015.
65 Nurka C. Shame and disgrace in Australian football culture: rape claims and public affect. Womens Stud Int Forum 2013:38:43-51.

66 Hartill M. The sexual abuse of boys in organized male sports. Men Masc 2009:12:225-49.

67 Alexander K, Stafford A, Lewis R. The experiences of children participating in organised sport in the UK. London, UK: National Society for the Prevention of Cruelty to Children, 2011.

68 Van Niekerk RL, Rzygula R. The perceptions and occurrence of sexual harassment among male student athletes with male coaches. Afr J Phys Health Educ Recreat Dance 2010;16:549.

69 Parent S, Lavoie F, Thibodeau ME, et al. Sexual violence experienced in the sport context by a representative sample of Quebec adolescents. I Interpers Viol 2015:1-21.

70 Brackenridge $\mathrm{CH}$, Kirby S. Playing safe: assessing the risk of sexual abuse to elite child athletes. Int Rev Sociol Sport 1997;32:407-18.

71 Fletcher S. Touching practice and physical education: deconstruction of a contemporary moral panic. Sport Educ Soc 2013;18:694-709.

72 Cense $\mathrm{M}$, Brackenridge $\mathrm{CH}$. Temporal and developmental risk factors for sexual harassment and abuse in sport. Eur Phy Educ Rev 2001;7:61-79.

73 Crosset TW. Male athletes' violence against women: a critical assessment of the athletic affiliation, violence against women debate. Quest 1999:51:244-57.

74 Stewart C. The negative behaviors of coaches: "Don't be this guy!" Phys Educ 2013;70(1):1.

75 Lindhorst L. Behind the mask of glory: combating child abuse in Olympic boarding schools. George Washington Int Law Rev 2015;47:353.

76 Marasescu MR. The role of hostile and instrumental aggression in sport. Linguist Philos Investig 2014;13:170.

77 East J. The causes of violence in sport: who is to blame? In: Brackenridge $\mathrm{CH}$, Kay T, Rhind D, eds. Sport, children's rights and violence prevention: a sourcebook on global issues and local programmes. London, UK: Brunel University Press, 2012:18-24.

78 Schot N. Negligent liability in sport. QLD, Australia: Bond University, 2005.

79 IOC. Olympic movement medical code. Lausanne, Switzerland: International Olympic Committee, 2009.

80 Tiivas A, Billington-Wood C. Key themes and integrity threats for elite sport. London, UK: National Society for the Prevention of Cruelty to Children, 2015.

81 Lang M. Adult-child touch in sport. In: Turner D, ed. Sports Coach UK, 2015. https://www.youtube.com/watch?v=-RzC7RCVxwE\&feature=youtu.be $\% 5 d$

82 Holman M. Female and male athletes' accounts and meanings of sexual harassment in Canadian interuniversity athletics (Doctoral dissertation). In press, 1995.

83 Dixon N. Trash talking, respect for opponents and good competition. Sport Ethics Philos 2007;1:96-106.

84 Rainey DW. Sport's officials' reports of hearing trash talk and their responses to trash talk. J Sport Behav 2012;35:78-93.

85 ACMA. Internet use and the social networking by young people. Australian Communications and Media Authority, 2008.

86 Campbell AJ, Robards F. Using technologies safely and effectively to promote young people's wellbeing: a better practice guide for services. NSW, Australia: NSW Centre for the Advancement of Adolescent Health (Westmead) and the Young and Well Cooperative Research Centre (Abbotsford), 2012.

87 Mulveen R, Hepworth J. Interpretative phenomenological analysis of participation in a pro-anorexia internet site and its relationship with disordered eating. $J$ Health Psychol 2006;11:283-96.

88 Davison CB, Stein CH. The dangers of cyberbullying. N Am J Psychol 2014;16:595.

89 LSEPS. European Union kids online report. In: Science LSoEaP, ed. London, England: London School of Economics and Political Science, 2014. http:/l Isedesignunitcom/EUKidsOnline/indexhtml? $\mathrm{r}=642014$

90 Van Volkom M, Stapley JC, Amaturro V. Revisiting the digital divide: generational differences in technology use in everyday life. N Am J Psychol 2014;16:557.

91 Cowie H. Cyberbullying and its impact on young people's emotional health and well-being. Psychiatrist 2013;37:167-70.

92 Boocock S. The child protection in sport unit. J Sex Aggress 2002;8:99-106.

93 Kavanagh EJ, Jones I. '\#Cyberviolence: developing a typology for understanding virtual maltreatment in sport. In: Rhind D, Brackenridge $\mathrm{CH}$, eds. Researching and enhancing athlete welfare. London, UK: Brunel University Press, 2014:34-43.

94 McLean S. Cyberbullying an issue for sport. Sport Coach 2014;30.

95 UKCCIS. UK Council for Child Internet Safety (UKCCIS). UK, 2015

96 Interpol. Sextortion - questions and answers: Interpol (cited 24 January 2016). 2015. http://www.interpol.int/en/crime-areas/cybercrime/online-safety/sextortion

97 Lebel K, Danylchuk K. How Tweet it is: a gendered analysis of professional tennis players' self-presentation on Twitter. Int I Sport Commun 2012;5:461-80.

98 Pegararo A. Look who's talking — athletes on Twitter: a case study. Int I Sport Commun 2010;3:501-15.

99 WPTV. Man accused of stalking tennis star Serena Williams in Palm Beach Gardens. 2011. http://www.wptv.com/news/region-n-palm-beach-county/ palm-beach-gardens/man-accused-of-stalking-tennis-star-serena-williams-in-palmbeach-gardens 
100 UKCCIS. Child safety online: a practical guide for parents and carers whose children are using social media. London, UK: United Kingdom Council for Child Internet Safety, 2015.

101 Starr K. Safe4athletes: survey on types of harassment in sport Colorado springs. CO, USA: United States Olympic Committee, 2015 (cited 9 July 2015).

102 Rigby K. New perspectives on bullying. London, UK: Jessica Kingsley Publishers, 2002.

103 Olweus D. Bully/victim problems among schoolchildren: basic facts and effects of a school based intervention program. In: Pepler D, Rubin K, eds. The development and treatment of childhood aggression. Hillsdale, NJ, USA: Erlbaum, 1991:411-48.

104 Flaatten OR, Sandsleth G. Do you care? No bullying in upper secondary school: guidelines for school management and staff. In: Education Df, ed. Oslo, Norway: Norwegian Government, 2005.

105 USADA. TrueSport: 9 ways coaches can prevent and stop bullying in sport. CO, USA: United States Anti-Doping Agency, 2014. Accessed online: http://truesport. org/articles/coaches/9-ways-coaches-can-prevent-stop-bullying-sport/

106 Sabo D, Valiz P. Go out and play: youth sports in America. East Meadow, NY, USA: Women's Sports Foundation, 2008.

107 Denison E, Kitchen A. Out on the fields: the first international study on homophobia in sport. Epub: Repucom, 2015.

108 Lundy C. MCA. Hazy viewpoints: administrators' perceptions of hazing. Int J Sport Manag Mark 2010;7:119-31.

109 Wintrup G. Researching British university sport initiations (Doctoral Thesis). In press, 2011.

110 Kowalski C, Waldron J. Looking the other way: athletes' perceptions of coaches' responses to hazing. Int J Sports Sci Coach 2010;5:87-100.

111 Swigonski NL, Enneking BA, Hendrix KS. Bullying behavior by athletic coaches. Pediatrics 2014:133:273-5.

112 Bruner M, Munroe-Chandler K, Spink K. Entry into elite sport: a preliminary investigation into the transition experiences of rookie athletes. J App/ Sport Psychol 2008;20:236-52

113 Waldron J, Krane V. Whatever it takes: health compromising behaviors in female athletes. Quest 2005;57:315-29.

114 Johnson J, Holman M. Gender and hazing: the same but different. J Phys Educ Recreation Dance 2009;80:6-9.

115 Nuwer $\mathrm{H}$. Wrongs of passage: fraternities, sororities, hazing and binge drinking. Bloomingtom, IN, USA: Indiana University Press, 1999.

116 Sage L, Kavussanu M. Goal orientations, motivational climate, and prosocial and antisocial behaviour in youth football: exploring their temporal stability and reciprocal relationships. J Sport Sci 2008;26:717-32.

117 Kavussanu M, Stanger N, Boardley ID. The Prosocial and Antisocial Behaviour in Sport Scale: further evidence for construct validity and reliability. J Sport Sci 2013:31:1208-21.

118 Hodge K, Lonsdale C. Prosocial and antisocial behaviour in sport: the role of coaching style, autonomous vs. controlled motivation, and moral disengagement. J Sport Exerc Psychol 2011;33:527-47.

119 Curry T. Reply to "a conversation (re)analysis of fraternal bonding in the locker room". Sociol Sport J 2001;18:339-44.

120 Anderson E, Bullingham R. Openly lesbian team sport athletes in an era of decreasing homohysteria. Int Rev Sociol Sport 2015;50:647-60.

121 CPSU. International Safeguards for Children in Sport. NSPCC, 2014.

122 WHO. Adolescent development. In: Maternal n, child and adolescent health, ed. Geneva, Switzerland: World Health Organization, 2015.

123 AVERT. Age of consent for sexual intercourse. 2015. http://www.avert.org/sex-stis/ age-of-consent

124 End Child Pornography, Child Prostitution, and Trafficking of Children for Sexual Purposes. Retrieved: 13 April 2016 from http://www.ecpat.net

125 Archard D. Sexual consent. Boulder, CO, USA: Westview Press. 1998.

126 UNPRPD. UNPRPD Fund Annual Report. UN Partnership to Promote the Rights of Persons with Disabilities, 2015.

127 Sobsey D. Violence and abuse in the lives of people with disabilities: the end of silent acceptance? Baltimore, MD, USA: Paul H. Brooks, 1994.

128 Sobsey D, Doe T. Patterns of sexual abuse and assault. Sex Disabil 1991;9:243-59.

129 Sullivan PM, Knutson JF. Maltreatment and disabilities: a population based epidemiological study. Child Abuse Negl 2000;24:1257-73.

130 Rasmussen TJ, Bird MM, Dinesen C. Different. Just like you: a psychosocial approach promoting the inclusion of persons with disabilities. Copenhagen, Denmark: International Federation of Red Cross and Red Crescent Societies, 2015.

131 Valenti-Hein D, Schwartz L. The sexual abuse interview for those with developmental difficulties. Santa Barbara, CA, USA: James Stanfield Company, 1995.

132 Kerr A. Protecting disabled children and adults in sport and recreation-the guide. Leeds, UK: The National Coaching Foundation, 1999.

133 Everett C. South Africa progressive on LGBT rights but gays still battle for social reform. International Business Times. 201422 October. 2011. http://www.ibtimes. co.uk/south-africa-progressive-lgbt-rights-gays-still-battle-social-reform-1471213

134 Demers G. Homophobia in sport: fact of life, taboo subject. Can J Women Coaching 2006;6:1-13.
135 Griffin P. Strong women, deep closets-lesbians and homophobia in sport. Champaign, IL, USA: Human Kinetics, 1998.

136 Gall D. Play fair. Sportsnet, 2015.

137 CAAWS. Seeing the invisible, speaking about the unspoken: a position paper on homophobia. Ottawa, ON, Canada: Canadian Association for the Advancement of Women in Sport and Physical Activity, 2012.

138 Cashmore E, Cleland J. Glasswing butterflies: gay professional football players and their culture. J Sport Soc Issues 2011;35:420-36.

139 Fusco C, Kirby SL. Are your kids safe? Media representations of sexual abuse in sport. In: Scraton S, Watson B, eds. Sport, Leisure and Gendered Spaces: Leisure Studies Publication No. 67, 2000:43-72.

140 Tofler I, Morse EE. Interface between sport psychiatry and sports medicine. Clin Sports Med 2005;24:4

141 Leahy T. Working with adult athlete survivors of sexual abuse. In: Hanrahan SJ, Andersen MB, eds. Routledge handbook of applied sport psychology: a comprehensive guide for students and practitioners. London, UK: Routledge, 2010:303-12.

142 Burke M. Obeying until it hurts: coach-athlete relationships. J Philos Sp 2001;28:227-40.

143 Fasting K, Brackenridge $\mathrm{CH}$, Walseth $\mathrm{K}$. Consequences of sexual harassment in sport for female athletes. J Sex Aggress 2002;8:37-48.

144 Burke M. Sexual harassment in sport: impact, issues and challenges. J Philos Sport 2003;30:97-100.

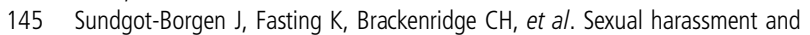
eating disorders in female elite athletes: a controlled study. Scand J Med Sci Sports 2003;13:330-5.

146 Yukhymenko-Lescroart MA, Brown ME, Paskus TS. The relationship between ethical and abusive coaching behaviors and student-athlete well-being. Sport Exerc Perform Psychol 2015:4:36-49.

147 WHO. World report on violence and health. Geneva, Switzerland: World Health Organization, 2002.

148 Mullen RE, Martin JL, Anderson JC, et al. The long-term impact of physical, emotional and sexual abuse of children: a community study. Child Abuse Negl 1996;20:7-21.

149 Higgins DJ, McCabe MP. Multi-type abuse and the long-term adjustment of adults. Child Abuse Rev 2000;9:6-18.

150 Kent A, Waller G. Childhood emotional abuse and eating pathology. Clin Psychol Rev 2000;20:887-903.

151 Hund AR, Espelage DL. Childhood emotional abuse and disordered eating among undergraduate females: mediating influence of alexithymia, and distress. Child Abuse Negl 2006:30:393-407.

152 Djeddah C, Facchin F, Ranzato C, et al. Child abuse: current problems and key public health challenges. Soc Sci Med 2000;51:905-15.

153 Marks S, Mountjoy M, Marcus M. Sexual harassment and abuse in sport: the role of the team doctor. Br J Sports Med 2012;46:905-8.

154 Stirling A, Kerr G. Sport psychology consultants as agents of child protection. J Appl Sport Psychol 2010;22:305-19.

155 Valovich McLeod TC, Decoster LC, Loud KJ, et al. National Athletic Trainers' Association position statement: prevention of pediatric overuse injuries. J Ath/ Train 2011;46:206-20.

156 DiFiori JP, Benjamin HJ, Brenner J, et al. Overuse injuries and burnout in youth sport: a position statement from the American Medical Society for Sports Medicine. Clin J Sport Med 2014;24:3-20.

157 Jayanthi NA, LaBella CR, Fischer D, et al. Sports-specialized intensive training and the risk of injury in young athletes: a clinical case control study. Am J Sports Med 2015;43:794-801.

158 Chaplo SD, Kerig PK, Bennett DC, et al. The roles of emotion dysregulation and dissociation in the association between sexual abuse and self-injury among juvenile justice-involved youth. J Trauma Dissociation 2015;16:272-85.

159 Bucchianeri MM, Eisenberg ME, Wall MM, et al. Multiple types of harassment: associations with emotional well-being and unhealthy behaviors in adolescents. J Adolesc Health 2014;54:724-9.

160 Ford JD, Góomez JM. Self-injury and suicidality: the impact of trauma and dissociation. J Trauma Dissociation 2015;16:225-31.

161 Moushey B, Dvorchak B. Game over: Jerry Sandusky, Penn state, and the culture of silence. New York, NY, USA: William Morrow, 2012.

162 Fasting K, Brackenridge CH, Walseth K. Women athletes' personal responses to sexual harassment in sport. J App/ Sport Psychol 2007;19:419-33.

163 Leahy T. Safeguarding child athletes from abuse in elite sport systems: the role of the sport psychologist. In: Gilbourne D, Andersen AM, eds. Critical essays in applied sport psychology. Champaign, IL, USA: Human Kinetics, 2011:251-66.

164 WADA. 2014 anti-doping testing figures report. Montreal, QC, Canada: World Anti Doping Agency, 2014.

165 WADA. 2013 anti-doping rule violations (ADRVs) report. Montreal, QC, Canada: World Anti Doping Agency, 2013.

166 Leahy T. Preventing the sexual abuse of young people in Australian sport. Sport Educator 2001;13:28-31. 
167 Parent S, Demers G. Sexual abuse in sport: a model to prevent and protect athletes. Child Abuse Rev 2001;20:120-33.

168 Lang M, Hartill M, eds. Safeguarding, child protection and abuse in sport: international perspectives in research, policy and practice. London, UK: Routledge, 2014.

169 Safe Sport International declaration and principles. London, United Kingdom: Safe Sport International, 2015.

170 USOC. Working group for safe training environments: recommendations to the USOC Board of Directors. CO, USA: United States Olympic Committee, 2010.

171 IOC. Sexual Harassment and Abuse educational program. International Olympic Committee, 2014

172 Brackenridge $\mathrm{CH}$. Ending violence against athletes. J Int Centre Sport Secur 2015:2:18-23.

173 Laws DR. Sexual offending as a public health problem: a North American perspective. J Sex Aggress 2000;5:30-44.

174 USOC. Coaching ethics code. Colorado Springs, CO, USA: United States Olympic Committee, 2000.

175 Maffulli N. Human rights in youth sports. Br I Sports Med 2007;41:59-60.

176 Brackenridge $\mathrm{CH}$, Pitchford A, Wilson M. Respect: results of a pilot project designed to improve behaviour in English football. Manag Leisure Int J 2011;16:175-91.

177 Korea NHRC. Guidelines: human rights in sports. Seoul, South Korea: National Human Rights Commission for the Republic of Korea, 2011.

178 Singh PC. 'Extreme' parents and sport: a socio-legal perspective. South Afr J Res Sport Phys Educ Recreation 2005;27:83-99.

179 CBS. CBS news forty eight hours: child sexual abuse and sports: resources. A list of organizations offering important prevention information and support. CBS News, 2015.

180 Kainz A. Sport respects your rights-the project. Wien, Austria: Sportunion Österreich, 2015. http://sport-respects-your-rights.eu/. 2015 (cited 9 July 2015).

181 NSPCC. Child abuse in a sports setting. National Society for the Prevention of Cruelty to Children Child Protection in Sport Unit, 2015.

182 United Nations Women. Sexual Harassment in Sport [Internet]. 2015 (cited 9 July 2015).

183 RCIRCSA. Royal commission into institutional responses to child sexual abuse. Australian Government, 2015 (cited 12 December 2015). https://www. childabuseroyalcommission.gov.au/

184 IICSA. Independent inquiry into child sexual abuse. Australian Government, 2015 (cited 12 December 2015).

185 Tenenbaum G, Stewart E, Singer RN, et al. Aggression and violence in sport: an ISSP position stand. Sport Psychol 1997;11:1-7.

186 Wells MS, Ruddell E, Paisley K. Creating an environment for sportsmanship outcomes: a systems perspective; systems modeling can guide the changes needed to improve the sport environment. J Phys Educ Recreation Dance 2006;77:13.

187 Connor J. The athlete as widget: how exploitation explains elite sport. Sport Soc 2009;12:1369-77

188 Corlett JA. Economic exploitation in intercollegiate athletics. Sport Ethics Philos 2013;7:295-312.

189 Parent S, Hlimi KE. Athlete protection in Quebec's sport system: assessments, problems, and challenges. J Sport Soc Issues 2013;37:284-96.

190 Fasting K, Sand T. Narratives of sexual harassment experiences in sport. Qual Res Sport Exerc Health 2015;7:573-88.

191 ASC. Play by the rules: making sport inclusive, safe and fair. Australian Sports Commission, 2015.

192 WSI. The Sexual Harassment Task Force: brochure on sexual harassment and abuse in sport. In: International W, ed. WA, USA: WomenSport International, 2007.

193 LaVetter D, Stahura KA. Negligent hiring in youth sports: background screening of volunteers. J Youth Sports 2010:5:9-15.

194 Parent S. Disclosure of sexual abuse in sport organizations: a case study. I Child Sexual Abuse 2011:20:322-37.

195 Chroni S, Fasting K, Hartill M, et al. Prevention of sexual and gender harassment and abuse in sports: initiatives in Europe and beyond. Frankfurt, Germany: Deutsche Sportjugend im Deutschen Olympischen Sportbund, 2012.

196 Grevers A. Safe sport: working to eradicate sexual abuse from swim sphere. Swimming World. Published online 8 April 2015. Retrieved 16 February 2016/. from: https://www.swimmingworldmagazine.com/news/safe-sport-working-toeradicate-sexual-abuse-from-swim-sphere/

197 SR. Sports resolutions londo. UK: Sports Resolutions, 2015.

198 WSF. Women's sports foundation. New York, NY, USA: Women's Sports Foundation, 2015.

199 Silent Edge. Abuse and harassment in figure skating. 2015. http://www.silentedge.org/index.html
200 Campo S, Poulos G, Sipple J. Prevalence and profiling: hazing among college athletes and points of intervention. Am J Health Behav 2005;29:137-49.

201 Capretto AD, Keeler LA. Examination of a hazing workshop intervention for intercollegiate sport club athletes. Recreational Sports J 2012;36:113-26.

202 Bringer JD, Brackenridge CH, Johnston LH. Defining appropriateness in coach-athlete sexual relationships: the voice of coaches. I Sex Aggress 2002;8:83-98.

203 Piper H, Garratt D, Taylor B. Child abuse, child protection, and defensive 'touch' in PE teaching and sports coaching. Sport Educ Soc 2013b;18:583-98.

204 Piper H, Garratt D, Taylor B. Hands off! The practice and politics of touch in physical education and sports coaching. Sport Educ Soc 2013a;18: 575-82.

205 Bryan C, Sims S. Appropriate and inappropriate practices for coaching female athletes. Strateg A J Phys Sport Educ 2014;27:13-17.

206 Duda J. Empowered coaching Birmingham. UK: University of Birmingham School of Sport and Exercise Sciences, 2015 (cited 5 August 2015).

207 PSA. Youth sexual abuse prevention policy and procedures mountain view. CA, USA: Positive Coaching Alliance, 2015.

208 PSA. Protecting youth athletes from abuse: youth sports leaders mountain view. CA, USA: Positive Coaching Alliance, 2015.

209 OMTCS. Coach's notes: preventing sexual abuse of children in sport Toronto. Ontario, Canada: Ontario Ministry of Tourism, Culture and Sport, 2015.

210 SquashCanada. Sexual abuse in amateur sports: a guide to prevention and intervention developed for sports administrators. Sports Branch of the Ministry of Municipal Affairs in co-operation with the Communications Branch, 1994

211 Malkin $\mathrm{K}$, Johnston $\mathrm{LH}$, Brackenridge $\mathrm{CH}$. A critical evaluation of training needs for child protection in UK sport. Manag Leisure Int I 2000;5:151-60.

212 Brackenridge $\mathrm{CH}$, Bringer JD, Bishopp D. Managing cases of abuse in sport. Child Abuse Rev 2005;14:259-74.

213 LA84. Resource guide on preventing child sexual abuse in youth sports. In: Foundation L, ed. CA, USA: LA84 Foundation, 2015.

214 Moorman AM, Masteralexis LP. An examination of the legal framework between title VII and title IX sexual harassment claims in athletics and sport settings: emerging challenges for athletics personnel and sport managers. J Legal Aspects Sport 2008;18:1-37.

215 McGlone CA. Hazy viewpoints: administrators' perceptions of hazing. Int I Sport Manag Mark 2010;7:119-31.

216 Noble J, Vermillion M. Youth sport administrators' perceptions and knowledge of organizational policies on child maltreatment. Child Youth Serv Rev 2014;38:52-7.

217 Brackenridge $\mathrm{CH}$. Healthy sport for healthy girls? The role of parents in preventing sexual abuse in sport. Sport Educ Soc 1998;3:59-78.

218 Wiersma LD, Sherman CP. Volunteer youth sport coaches' perspectives of coaching education/certification and parental codes of conduct. Res Q Exerc Sport 2005;76:324-38.

219 Velasquez BJ, Drummond J. Sexual harassment in the athletic training room: implications for athletic trainers. Athl Ther Today 2003;8:20-3.

220 ITF. Player welfare. International Tennis Federation, 2014 (cited 8 May 2014).

221 Kamm RL. A developmental and psychoeducational approach to reducing conflict and abuse in little league and youth sports: the sport psychiatrist's role. Sports Psychiatry 1998;7:819-918.

222 FEPSAC. Position paper \# 6: sexual exploitation in sport, 2002. European Federation of Sport Psychology, 2002.

223 Rossato C, Brackenridge $\mathrm{CH}$. Child protection training in sport-related degrees and initial teacher training for physical education: an audit. Child Abuse Rev 2009; 18:81-93.

224 Osborne BA. Eliminating sexual violence in schools: implications for athletics administrators in the United States. Int Sports Law J 2013;13:9-17.

225 USGAO. Youth athletes: sports programs' guidance, practices, and policies to help prevent and respond to sexual abuse. In: GAO, ed. United States Government Accountability Office, 2015:418.

226 Van Niekerk L. Protecting athletes from sexual harassment and abuse in South Africa. In: Lang M. Hartill M, eds. Safeguarding, child protection and abuse in sport: international perspectives in research, policy and practice. London, UK: Routledge, 2014:88-96.

227 Van Rheenen D. Exploitation in college sports: race, revenue, and educational reward. Int Rev Sociol Sport 2013;48:550-71.

228 CAS. History of the CAS Lausanne. Switzerland: Court of Arbitration for Sport, 2015 (cited 17 January 2016).

229 Shogan D. Sport ethics in context. Toronto, ON, Canada: Canadian Scholars Press, 2007. 